\title{
Lipid screening in an elderly population: difficulty in interpretation and in detection of occult metabolic disease
}

\author{
A F Winder, C Jagger, D P Garrick, D T Vallance, P F Butowski, J Anderson, \\ M Clarke
}

\begin{abstract}
Aims-To determine lipid profiles and associations with other metabolic disease in a representative British elderly population.

Methods-Part of a prevalence survey of dementia in all $75+$ year olds conducted from the large general practice serving the town and surrounding area of Melton Mowbray, Leicestershire (the M-old study). Patients $(n=224)$ aged from 75 to 98 years, and representative of the overall population, also provided pre-prandial blood samples on which various age and nutrition related analytes were determined. These included documented medical history, thyroid stimulating hormone (TSH), glucose, immunoglobulins, and lipid profile in plasma.
\end{abstract}

Results-Cholesterol and lipid variables showed wide scatter, with some negative trends but no significant associations with age for total cholesterol, high density lipoprotein (HDL) cholesterol, the ratio of total to HDL cholesterol or triglycerides. Women had significantly higher concentrations of total and HDL cholesterol at all ages. Serum TSH was above $6.0 \mathrm{mU} /$ 1 in 10/205 patients, random glucose was above $11.2 \mathrm{mmol} / \mathrm{l}$ in nine of 207 patients, borderline dysglobulinaemia was present in four of 210 patients, all without correlation with cholesterol concentrations.

Conclusion-This British data is consistent with an inverse correlation between survival and cholesterol, but wide scatter restricts reliance on single result lipid data in individual patient management. Random lipid screening is also unhelpful, inefficient and without added value in revealing other age related and unrecognised occult metabolic disease.

(f Clin Pathol 1996;49:278-283)

Keywords: old age, lipids, lipoproteins, lipid screening, diabetes, thyroid function, immunoglobulins, secondary dyslipoproteinaemia.

Clinical cardiovascular disease is the major cause of death and disability in elderly populations: health checks and patient interest have increased the extent of lipid screening in the elderly. Most, but not all, studies have shown that associations with lipid profiles still apply, particularly in men, ${ }^{1-5}$ although protocols for lipid screening and benefits of lipid treatment in old age are not defined ${ }^{67}$ Lipaemia can also reveal and be secondary to other metabolic disorders including diabetes, ${ }^{8}$ hypothyroidism ${ }^{9}$ and immunoglobulin disorders expressed grossly as excess or immunosuppression. ${ }^{1011}$ Cholesterol testing of all age groups in general practice has shown a low yield of such primary disorders, ${ }^{12}$ but as these disorders are age related and have potential for treatment, lipid screening of the elderly could acquire further added value if it led to their diagnosis.

There are very little data on lipid profiles in British elderly populations. We have surveyed lipid profiles and some metabolic associations for a sample of a representative British population aged 75 years and over who were registered with a general practice serving the town of Melton Mowbray, Leicestershire, and who had taken part in a total population survey of elderly people. ${ }^{13}$ This is not a management survey, but an attempt to obtain basic information on which future management decisions may be based.

\section{Methods}

CLINICAL METHODS: RECRUITMENT AND ASSESSMENT OF SUBJECTS

The study population forms part of a two-stage prevalence survey of dementia conducted from the large general practice ( 12 doctors) which serves the town and surrounding area of Melton Mowbray, Leicestershire. The first stage of the study consisted of a home interview with all patients registered with the practice and aged 75 years or over on the 31st December 1987. The interview schedule covered the areas of physical health, contact with family and friends and use of services. Full details of the full survey population have already been published..$^{13}$ Melton Mowbray was selected partly because the population was then representative of England and Wales as a whole, in terms of age, sex and social class, and of ethnic distribution with approximately $1 \%$ of the population of Polish extraction and no other significant external group. The study was ap- 
proved by the Leicester District ethics committee.

The Mini-Mental State Examination (MMSE) of Folstein ${ }^{14}$ in the first stage formed the basis for entry into the second stage of the survey. All those scoring 21 or under (out of a total score of 30) on the MMSE, one in two of those scoring 22 or 23 and one in 10 of the remainder were invited to undergo a full psychiatric assessment using the CAMDEX ${ }^{15}$ by a trained clinician. The CAMDEX schedule encompasses items on past medical history, including cardiovascular events of angina or previous myocardial infarction and metabolic disorders such as diabetes. A brief medical examination was also undertaken. Full details of the results of this phase of the survey can be found elsewhere. ${ }^{16}$ At the end of the second interview, subjects were asked whether they would give a blood sample: data on those who agreed are presented here.

\section{LABORATORY METHODS}

Venous blood obtained by venepuncture without prolonged use of a tourniquet was collected into heparin tubes for lipid, protein and thyroid assays, and into fluoride tubes for glucose. Samples were pre-prandial but not specifically fasting as this was felt to be a difficult and unreliable restriction for the population involved. Occasional samples were insufficient to allow analysis for all analytes.

Lipid and other laboratory methods were as described for another larger population study, ${ }^{17}$ also conducted in part through general practices in Leicestershire, involving the same laboratory and over the same time period. Concentrations of cholesterol and triglycerides in plasma were measured using enzymatic colorimetric methods, as was high density lipoprotein (HDL) cholesterol after heparinmanganese precipitation, all on a Cobas Fara analyser. HDL cholesterol data represent the average of duplicate assays of single samples. Glucose concentrations were measured by an enzymic oxidase method (Technicon). Thyroid status was evaluated by determination of thyroid stimulating hormone (TSH) by a high sensitivity method using time-lapsed immunofluorescence (Delfia). Total protein in plasma was determined by the biuret method, albumin by dye-binding (BCG) and total globulins by subtraction. Performance with all assays was reviewed through national and specialist interest quality assurance schemes.

Table 1 Demographic characteristics of the total 1988 study population, those subjects assessed by CAMDEX and the subset who agreed to give a blood sample

\begin{tabular}{lccc}
\hline & $\begin{array}{l}\text { Total 1988 study } \\
\text { population } \\
(n=1579)\end{array}$ & $\begin{array}{l}\text { Assessed by } \\
\text { CAMDEX } \\
(n=438)\end{array}$ & $\begin{array}{l}\text { Blood sampled } \\
(n=224)\end{array}$ \\
\hline Demographic characteristics & & & \\
Age in years (\%) & $760(48)$ & $148(34)$ & $71(32)$ \\
$75-79$ & $519(33)$ & $144(33)$ & $70(31)$ \\
$80-84$ & $227(14)$ & $103(24)$ & $60(27)$ \\
$85-89$ & $73(5)$ & $43(10)$ & $23(10)$ \\
$\begin{array}{l}\text { Sex }(\%) \\
\text { male } \\
\text { female }\end{array}$ & $541(34)$ & $119(27)$ & $64(29)$ \\
$\begin{array}{l}\text { Where interviewed (\%) } \\
\text { community } \\
\text { institution }\end{array}$ & $1038(66)$ & $319(73)$ & $160(31)$ \\
\hline & $1500(95)$ & $377(86)$ & $183(82)$ \\
\hline
\end{tabular}

Apolipoprotein $E$ profiles

The E-4 allele is associated with Alzheimers's disease and inversely with survival. Lipoprotein (a) concentrations - reported to have less clinical impact than in younger populations ${ }^{18}$ although lower concentrations could suggest an effect on survival ${ }^{19}$-were not investigated.

\section{STATISTICAL METHODS}

Differences in lipid concentrations between the sexes after adjustment for age and between age groups after adjustment for sex were assessed by $\mathrm{F}$ tests in an analysis of variance. Analysis of the association between lipid profiles and both hyperglycaemia and biochemical thyroid status was by logistic regression with adjustment for age and sex. Significance of the lipid concentrations was assessed by the Wald $\chi^{2}$ statistic. All analyses were weighted according to the sampling probability between stages 1 and 2 so that results are representative of the total population. This method will slightly deflate standard errors and result in too many variables being considered significant (at a $5 \%$ level) in regression models. Where the unweighted and weighted analyses differed, this is indicated in the text.

\section{Results}

One thousand, eight hundred and ninety people aged 75 years and over were identified on the age/sex register of the general practice and 1579 were interviewed in the first stage with a refusal rate of $5 \% .{ }^{13}$ Of these 1579,438 completed the CAMDEX assessment forming the second stage of the study. As the CAMDEX group had greater numbers with dementia than in the total population, the demographic characteristics of the group reflected this with more of the very elderly, women and non-community dwellers (table 1). However, after weighting by the sampling procedure for the second stage, there was no evidence that the CAMDEX group were different from the total population on these and other demographic characteristics or physical health. Lipid profiles have also been shown to be unrelated to the development of dementia. ${ }^{4}$

In total, 224 of those completing the CAMDEX assessment agreed to give a blood sample and comprise the present study population. The demographic characteristics of these 224 patients are shown in table 1 and they did not differ significantly from those refusing in these or any other demographic variables or physical or mental health. We believe, therefore, that sampling bias has been addressed and that the survey data are representative of the overall population of Melton Mowbray and thus of England and Wales at that time.

\section{LIPID PROFILES}

The samples collected were suitable for determination of total cholesterol (TC) and triglycerides for 59 men and 153 women, with HDL cholesterol and TC:HDL cholesterol ratios for 42 men and 96 women. As blood sampling was not specifically in the fasting state, triglyceride data have not been analysed 
Table 2 Weighted age and sex specific mean values and standard deviations of total cholesterol (TC), HDL cholesterol, ratio of total to HDL cholesterol (TC:HDL cholesterol) and triglycerides

\begin{tabular}{|c|c|c|c|c|c|c|}
\hline \multirow[b]{3}{*}{ Lipid } & \multicolumn{6}{|c|}{ Age group (years) } \\
\hline & \multicolumn{3}{|l|}{ Men } & \multicolumn{3}{|l|}{ Women } \\
\hline & $75-79$ & $80-84$ & $85+$ & $75-79$ & $80-84$ & $85+$ \\
\hline \multicolumn{7}{|c|}{ Total cholesterol } \\
\hline Mean & $6 \cdot 31$ & $6 \cdot 49$ & $5 \cdot 57$ & 6.89 & 6.59 & $6 \cdot 70$ \\
\hline SD & $1 \cdot 11$ & 1.01 & $0 \cdot 83$ & $1 \cdot 30$ & 1.03 & $1 \cdot 20$ \\
\hline $\mathrm{N}^{*}$ & 25 & 19 & & & & 62 \\
\hline \multicolumn{7}{|c|}{ HDL cholesterol } \\
\hline Mean & $1 \cdot 23$ & $1 \cdot 19$ & 1.35 & $1 \cdot 34$ & $1 \cdot 54$ & 1.49 \\
\hline$S D$ & 0.31 & 0.23 & 0.33 & $0 \cdot 27$ & 0.32 & 0.37 \\
\hline $\mathrm{N}^{*}$ & 20 & 12 & 10 & 25 & 30 & 41 \\
\hline \multicolumn{7}{|c|}{ TC:HDL cholesterol ratio } \\
\hline Mean & $5 \cdot 29$ & $5 \cdot 45$ & $4 \cdot 20$ & 4.99 & $4 \cdot 33$ & $4 \cdot 89$ \\
\hline SD & $1 \cdot 26$ & 0.94 & 1.84 & 1.05 & 0.98 & 1.65 \\
\hline $\mathrm{N}^{*}$ & 20 & 12 & 10 & 25 & 30 & 41 \\
\hline \multicolumn{7}{|c|}{ Triglycerides } \\
\hline Mean & $2 \cdot 18$ & $2 \cdot 08$ & 2.03 & $2 \cdot 15$ & $1 \cdot 68$ & $2 \cdot 25$ \\
\hline SD & $1 \cdot 03$ & 0.87 & $1 \cdot 19$ & $1 \cdot 18$ & 0.61 & $1 \cdot 17$ \\
\hline $\mathrm{N}^{*}$ & 25 & 19 & 15 & 45 & 46 & 62 \\
\hline
\end{tabular}

* Unweighted.

\section{NON-FASTING GLUCOSE}

Glucose concentrations and associated lipid profiles were recorded for 56 men and 151 women. Glucose concentrations greater than $11.2 \mathrm{mmol} / \mathrm{l}$ were found in two men and seven women (total nine cases) of whom six were known diabetics. Glucose concentrations in excess of $8.0 \mathrm{mmol} / 1$ were found in nine of 56 men, 17/151 women (total 26 cases) of whom nine were known diabetics. Details and clinical status of these 26 cases at the time of testing are shown in table 3.

After adjustment for age and sex, hyperglycaemia (defined as glucose in excess of $8 \mathrm{mmol} / \mathrm{l}$ ) was significantly associated with decreased total cholesterol (Wald $\chi^{2}=8 \cdot 97, \mathrm{DF}=$ 1, $\mathrm{p}=0.003$ ), decreased HDL cholesterol (Wald $\chi^{2}=7 \cdot 46, \mathrm{DF}=1, \mathrm{p}=0.006$ ) and increasing triglycerides (Wald $\chi^{2}=67 \cdot 65, \mathrm{DF}=$ $1, \mathrm{p}<0.0001)$. In the unweighted analyses only the relation with triglycerides remained significant. Four cases were found with hyperglycaemia and HDL cholesterol below $1.0 \mathrm{mmol} / \mathrm{l}$ and all were known diabetics. TC, HDL cholesterol, TC:HDL cholesterol and triglycerides are shown in table 2, weighted to be representative of the total population aged 75 and over. For cholesterol, the highest value was $10.0 \mathrm{mmol} / \mathrm{l}$ (394 $\mathrm{mg} \%)$. Concentrations were above $8 \mathrm{mmol} / \mathrm{l}(315 \mathrm{mg} \%)$ in 17 female and two male participants, aged 75-90 years, including one female known diabetic and one male newly diagnosed as diabetic through hyperglycaemia. Data for cholesterol are shown in figs 1 and 2 .

The data are broadly in accord with projections from age/sex related trends previously recorded for a younger UK population, in which the present investigators and laboratory took part. ${ }^{17}$ Women had significantly higher concentrations of total $(\mathrm{F}=11 \cdot 40, \mathrm{DF}=1, \mathrm{p}=$ $0.0009)$ and HDL cholesterol ( $F=13.74$, $\mathrm{DF}=1, \mathrm{p}=0.0003)$. Trends are discussed: no significant relation between age and levels of any of the lipids was found.

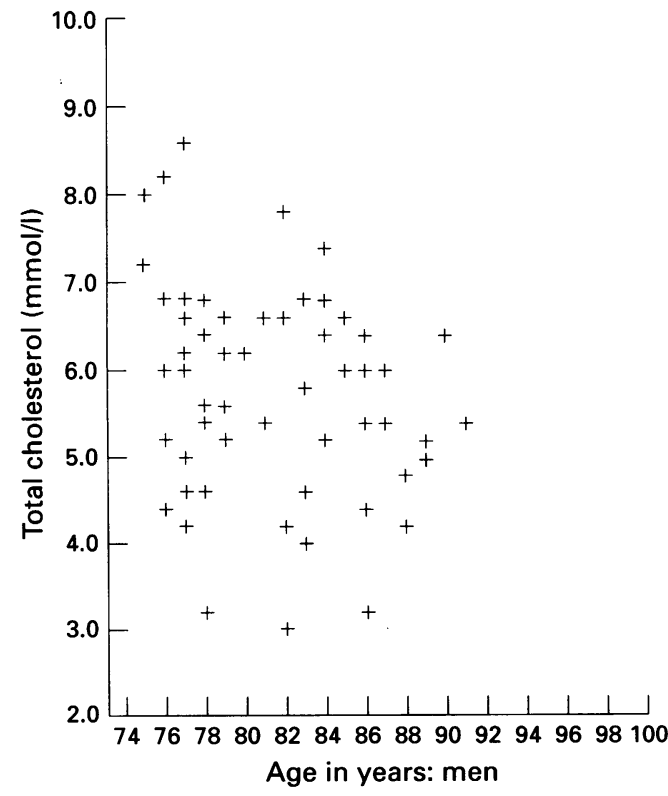

Figure 1 Values for total cholesterol in plasma for 59 men aged 75-91 years. Duplicate data points are not shown.

\section{THYROID FUNCTION STATUS}

As for glucose, the survey provided data on both ways to be reviewed. TSH at or in excess of $6.0 \mathrm{mU} / 1$ was recorded for $10(6.8 \%)$ of 147 participants, all women, none previously known or suspected to be hypothyroid. Data for $\mathrm{TSH}$ and associated lipid profiles and clinical status are shown in table 4 for these 10 women. Biochemical evidence of hypothyroidism was thus a feature of this population. However, after adjustment for age and sex, lipid profiles did not seem to be obviously related to thyroid biochemical status at the time of testing.



Figure 2 Values for total cholesterol in plasma for 153 women aged 75-98 years. Duplicate data points are not shown. TSH and on lipid profiles, allowing associations 
Table 3 Hyperglycaemia and associated dyslipoproteinaemia

\begin{tabular}{|c|c|c|c|c|c|}
\hline Participant & $\begin{array}{l}\text { Glucose } \\
\text { (mmolll) }\end{array}$ & $\begin{array}{l}\text { Cholesterol } \\
(\mathrm{mmol} / \mathrm{l})\end{array}$ & $\begin{array}{l}\text { Triglycerides } \\
(\mathrm{mmol} / \mathrm{l})\end{array}$ & $\begin{array}{l}\text { HDL cholesterol } \\
(\mathrm{mmol} / \mathrm{l})\end{array}$ & $\begin{array}{l}\text { Status before } \\
\text { test }\end{array}$ \\
\hline LF M76 & $20 \cdot 0$ & $4 \cdot 5$ & 1.9 & 0.99 & Known diabetic \\
\hline MF M84 & 18.5 & $6 \cdot 4$ & 3.8 & - & Unknown \\
\hline VB F84 & $16 \cdot 8$ & $6 \cdot 7$ & $2 \cdot 4$ & - & Not diabetic \\
\hline AW F80 & $16 \cdot 8$ & $4 \cdot 3$ & $3 \cdot 0$ & 0.66 & Known diabetic \\
\hline FL F85 & $15 \cdot 8$ & $6 \cdot 0$ & $4 \cdot 0$ & 0.90 & Known diabetic \\
\hline IW F77 & $15 \cdot 3$ & 6.5 & $5 \cdot 4$ & $1 \cdot 00$ & Not diabetic \\
\hline JM F83 & $13 \cdot 1$ & $9 \cdot 5$ & $3 \cdot 2$ & $1 \cdot 20$ & Known diabetic \\
\hline HH F78 & $13 \cdot 1$ & $7 \cdot 1$ & $1 \cdot 2$ & 1.54 & Known diabetic \\
\hline DE F82 & $11 \cdot 3$ & $5 \cdot 8$ & $1 \cdot 2$ & - & Known diabetic \\
\hline AM F76 & $10 \cdot 8$ & 6.9 & $2 \cdot 3$ & 1.43 & Not diabetic \\
\hline WT M80 & $10 \cdot 7$ & $6 \cdot 2$ & $1 \cdot 1$ & 1.55 & Known diabetic \\
\hline CW M85 & $10 \cdot 7$ & $6 \cdot 0$ & 4.5 & 0.93 & Known diabetic \\
\hline MS F85 & $10 \cdot 2$ & $6 \cdot 4$ & $4 \cdot 7$ & 1.33 & Known diabetic \\
\hline RG M88 & $10 \cdot 2$ & $4 \cdot 2$ & $2 \cdot 0$ & 1.59 & Not diabetic \\
\hline HT F76 & $9 \cdot 6$ & $6 \cdot 1$ & $3 \cdot 2$ & - & Not diabetic \\
\hline AC M86 & $9 \cdot 5$ & $5 \cdot 4$ & 1.9 & 1.99 & Not diabetic \\
\hline MS F82 & $9 \cdot 4$ & $4 \cdot 6$ & $1 \cdot 0$ & $1 \cdot 40$ & Not diabetic \\
\hline$-M 80$ & $9 \cdot 3$ & $6 \cdot 6$ & 1.6 & - & Not diabetic \\
\hline - M82 & $9 \cdot 2$ & 6.6 & $1 \cdot 2$ & - & Not diabetic \\
\hline RS F87 & $9 \cdot 0$ & $5 \cdot 7$ & $4 \cdot 8$ & - & Not diabetic \\
\hline EC F85 & $8 \cdot 8$ & $10 \cdot 0$ & $6 \cdot 0$ & $1 \cdot 05$ & Not diabetic \\
\hline MC F79 & $8 \cdot 8$ & $7 \cdot 6$ & $3 \cdot 8$ & 1.02 & Not diabetic \\
\hline- F75 & $8 \cdot 6$ & $5 \cdot 7$ & $1 \cdot 8$ & - & Known diabetic \\
\hline - F87 & $8 \cdot 2$ & $7 \cdot 9$ & $3 \cdot 1$ & $1 \cdot 26$ & Not diabetic \\
\hline EB F89 & $8 \cdot 2$ & $6 \cdot 0$ & $2 \cdot 8$ & - & Not diabetic \\
\hline JP M 89 & $8 \cdot 1$ & $5 \cdot 3$ & $1 \cdot 2$ & 1.50 & Not diabetic \\
\hline
\end{tabular}

PLASMA PROTEINS

Dysglobulinaemia defined as concentrations at or marginally beyond the reference range of $20-40 \mathrm{~g} / 1$ was present in one of 58 men and three of 152 women tested. Details with associated lipid profiles are shown in table 5 . Dyslipoproteinaemia as hypercholesterolaemia was associated with borderline dysglobulinaemia in one participant only, who also had known diabetes mellitus (fasting blood glucose $13 \cdot 1 \mathrm{mmol} / \mathrm{l})$.

\section{OTHER CARDIOVASCULAR STATUS AT ENTRY}

Myocardial infarction or angina

This was recorded for only six male and eight female participants at entry. Three of the six men had known hypertension, one of whom was also a known diabetic. Three of the eight women had known hypertension, one of whom had a documented stroke, and one further case was then newly diagnosed as diabetic.

Table 4 Thyroid status and associated dyslipoproteinaemia

\begin{tabular}{|c|c|c|c|c|}
\hline Participant & $\begin{array}{l}T S H \\
(m U / l)\end{array}$ & $\begin{array}{l}\text { Cholesterol } \\
\text { (mmolll) }\end{array}$ & $\begin{array}{l}\text { Triglycerides } \\
(\text { mmolll })\end{array}$ & $\begin{array}{l}\text { HDL cholesterol } \\
\text { (mmolll) }\end{array}$ \\
\hline $\begin{array}{l}\text { NT F76 } \\
\text { MM F81 } \\
\text { AF F86 } \\
\text { HS F85 } \\
\text { GL F83 } \\
\text { DD F83 } \\
\text { AR F92 } \\
\text { FS F87 } \\
\text { EA F83 } \\
\text { IW F77 }\end{array}$ & $\begin{array}{r}61 \cdot 0 \\
29 \cdot 0 \\
21 \cdot 3 \\
16 \cdot 9 \\
13 \cdot 7 \\
9 \cdot 7 \\
9 \cdot 6 \\
8 \cdot 4 \\
6 \cdot 3 \\
6 \cdot 0\end{array}$ & $\begin{array}{l}6 \cdot 8 \\
6 \cdot 3 \\
8 \cdot 2 \\
6 \cdot 4 \\
6 \cdot 8 \\
5 \cdot 5 \\
5 \cdot 1 \\
6 \cdot 4 \\
7 \cdot 9 \\
6 \cdot 5\end{array}$ & $\begin{array}{l}2 \cdot 4 \\
1.0 \\
1.6 \\
1.4 \\
2.0 \\
1.0 \\
1.0 \\
2 \cdot 3 \\
2.3 \\
5 \cdot 4\end{array}$ & $\begin{array}{l}1.27 \\
1.85 \\
\overline{1} \\
1.55 \\
1.56 \\
\overline{1} \\
\bar{y} \\
\overline{1} \\
1.00\end{array}$ \\
\hline
\end{tabular}

Table 5 Dysglobulinaemia and associated dyslipoproteinaemia

\begin{tabular}{lllll}
\hline Participant & $\begin{array}{l}\text { Globulins } \\
(\mathrm{g} / \mathrm{l})\end{array}$ & $\begin{array}{l}\text { Cholesterol } \\
(\text { mmolll) }\end{array}$ & $\begin{array}{l}\text { Triglycerides } \\
(\text { mmolll })\end{array}$ & $\begin{array}{l}\text { HDL cholesterol } \\
(\text { mmolll) }\end{array}$ \\
\hline JB F79 & 44 & $6 \cdot 6$ & $1 \cdot 2$ & $1 \cdot 44$ \\
JE F84 & 40 & $5 \cdot 1$ & 0.9 & $2 \cdot 3$ \\
LF M76 & 42 & $4 \cdot 5$ & $1 \cdot 9$ & $0.99^{*}$ \\
JM F83 & 19 & $9 \cdot 5$ & $3 \cdot 2$ & $1 \cdot 2^{*}$ \\
\hline
\end{tabular}

* Known diabetic.
Stroke

Stroke was recorded for one male and for 20 female participants, of whom 10 were known hypertensive, two were known hypertensive/ diabetic and two were known diabetic. Of the two women with myocardial infarction and stroke, one was a known diabetic, one a known hypertensive.

\section{Hypertension}

This was documented at entry for 12 men and 44 women, a total of 56 participants. Standard medication when used at that time was thiazide diuretics or beta blockers, agents with potential to distort lipid profiles. Concentrations of TC were therefore reviewed in comparison with age/sex quintiles for the overall group of participants as follows:

- age 75-80 years: men $(n=8)$ with a mean TC of $5.6 \mathrm{mmol} / 1$ which is on the mean of the trend line for age; women $(n=21)$ with a mean TC of $6.95 \mathrm{mmol} / 1,0.4 \mathrm{mmol} / 1$ above trend line for age;

- age 81-85 years: women $(n=14)$ with a mean TC of $6.4 \mathrm{mmol} / 1,0.05 \mathrm{mmol} / \mathrm{l}$ below the trend line for age;

- age 86-90 years: women $(n=7)$ with a mean TC of $6.4 \mathrm{mmol} / 1,0.1 \mathrm{mmol} / \mathrm{l}$ above the trend line for age. (Data on males above 80 years of age is not listed as these groups were restricted to one to three participants only.)

Thus for patients with known hypertension, TC concentrations were broadly in line with the age/sex trends of the overall population from which they were drawn.

Hormone replacement therapy was not a characteristic of the female participants.

\section{Discussion}

Our objective was to enlarge the data available on lipoprotein profiles and their metabolic associations in a British geriatric population, 
an essential pre-requisite to any considerations of management. From our study, total lipid concentrations showed wide scatter with "pudding" graphs as reported in other vertical surveys of elderly populations. ${ }^{17}$ Concentrations of TC for men and women in the $75+$ age group were slightly below the age/sex related trends recorded in a large national multicentre study of adults over the age range 21-59 years, to which we contributed, over an overlapping time period. ${ }^{17}$ This overall relation was also reported in one previous British study extending into old age, ${ }^{20}$ although Pocock and Seed $^{21}$ noted that TC concentrations recorded in 4376 men and women aged $65-74$ years showed an increase of $0 \cdot 16-0 \cdot 17 \mathrm{mmol} / 1$ at one year. Inversion of the relation between cholesterol and age at extremes of life as here was reported in surveys in North America and apparently represents both selection with earlier death at higher values, lipid profiles in the elderly having some associations with later outcome as in earlier life, and some natural fall with age. ${ }^{1-472223}$

Considering undetected hyperglycaemia and diabetes, levels of glucose concentrations above $8.0 \mathrm{mmol} / \mathrm{l}$ were found in nine of $56 \mathrm{men}$, and $17 / 155$ women (total of 26 cases, $12.3 \%$ ) of whom nine were known diabetics. Glucose concentrations above $11.2 \mathrm{mmol} / 1$ were found in two men, and seven women (total nine cases) of whom six were known diabetics. Triglyceride data are not well defined as noted above, but concentrations were higher in the hyperglycaemic group than in the overall population. There was no consistent difference between concentrations of total and HDL cholesterol for hyperglycaemic and other participants, but the four cases with hyperglycaemia and HDL cholesterol below $1.0 \mathrm{mmol} / 1$ were known diabetics. Concentrations of TC were not significantly different between groups and wide inter-individual variation was evident for all lipid markers. (Concentrations of glycosylated haemoglobin were not measured: these can correlate with concentrations of cholesterol in both normal and known diabetic populations. ${ }^{24}$ ) With data on both lipid profiles and concentrations of glucose, relations in either direction can be reviewed. For hyperglycaemic individuals identified in our survey, there were no close associations between lipid profiles and overall glucose status: lipoprotein profiles and particularly cholesterol concentrations were not obviously associated with or a marker for random sample hyperglycaemia.

Hypothyroidism can be associated with hypercholesterolaemia through impairment of receptor based clearance or of hepatobiliary metabolism. ${ }^{925}$ Most patients with mild subclinical hypothyroidism have lipoprotein profiles similar to those of normal controls and replacement is not recommended. ${ }^{26}$ Associations between hypercholesterolaemia and asymptomatic hypothroidism have been noted in some, but not all, surveys in the general population, but they are a feature of referrals to a lipid clinic. Thus, Ball et $a l^{9}$ found that $9.6 \%$ of a mixed group of adults below age 70 years of age contributing to a nutritional survey with concentrations of plasma cholesterol above $7 \mathrm{mmol} / 1$ had raised TSH above $6 \mathrm{mU} / 1$ and asymptomatic but biochemically definite or compensated hypothyroidism, not found in any participant with cholesterol below $4 \cdot 1 \mathrm{mmol} / \mathrm{l}$. Similar results were reported for a hyperlipidaemic adult population in Glasgow, ${ }^{27}$ and in new referrals to a lipid clinic, ${ }^{28-30}$ all over a wide age range. The criteria for selection are important. Our population was selected by age and not by hypercholesterolaemia, and with data on both lipid and thyroid status any relations can be reviewed from both perspectives. From table 4 it is clear that the lipid profile alone, and particularly raised total or HDL cholesterol, or both, was not a strong marker in individuals for any degree of unrecognised hypothyroidism.

Lipoprotein lipase activity can be directly or indirectly impaired in the presence of excess of immunoglobulins, with specific interactions with various components of the clearance pathway for triglyceride-rich lipoproteins. ${ }^{1011} \mathrm{But}$ dyslipoproteinaemic individuals in our population were not readily identified by association with dysglobulinaemia defined either through borderline values or deficiency with the potential to indicate immunosuppression.

Lipid profiles in the elderly are of special interest because of the burden of atherosclerotic disease expressed by our ageing population. ${ }^{1}$ Other markers of risk also apply and identification of diabetes and hypertension in particular as in our study may alert to that risk status independent of any association with lipid profiles. There are no clinical trial data on the benefits of lipid management in the elderly. ${ }^{31}$ Calculations of risk status and potential benefit can be made for the elderly but they are theoretical and unweighted for short life expectancy. ${ }^{32}$ At present, profiles have no clearly defined role in general clinical management, with or without active cardiovascular disease, except that falling concentrations of cholesterol can alert to malignancy. ${ }^{33}$ This may turn out to be the final position but the issue deserves further attention: the clinical consequences of atherosclerosis should not be seen as acceptable, perhaps even normal in the elderly as other active treatment-for example, by coronary surgery in selected cases can have clear benefits including enhanced longevity beyond that of their host general population. ${ }^{343}$ As clinical outcome after surgery for mixed age groups is related to lipid variables, ${ }^{3637}$ a key issue for the elderly may be to survive long enough to derive any benefit from medical intervention. Recent trials of the clinical benefits of modifying lipid profiles in middle aged men in secondary prevention, ${ }^{38}$ and in both men and women in primary prevention, ${ }^{39}$ have been encouraging for that age range, and also suggest that benefits may arise in less than one year. Considerations of toxicity in the elderly have also been reassuring ${ }^{40}$ and support extension of secondary prevention into older age groups, particularly if lead times for benefit are short. Haemostatic variables also need further evaluation as in the elderly they can be adverse, are related to lipid profiles, and in other groups 
have been shown to respond rapidly to lipid intervention. ${ }^{4142}$ But the main difficulties in defining clinical significance of lipid profiles in old age are that reference populations can show wide scatter as here, that reference "normal" ranges defined through population surveys with or without reference to clinical events differ from and cannot be simply extrapolated from those recorded for younger, generally much younger, age groups, and that values can differ greatly on repeat testing, ${ }^{43}$ compromising both confidence in a result and the range against which it is assessed. Difficulties of interpretation could perhaps be sidelined by replacement with selective and multifactorial screening programmes in early and middle age, with more secure associations with outcome and reduced interest in obtaining new data in later life. ${ }^{6}$ Apart from malignancy, this awkward variability may involve other general metabolic disorders, ${ }^{334}$ including asymptomatic hypothyroidism, diabetes and paraproteinaemia, and perhaps also antihypertensive medication, although for TC this was not a strong feature at recruitment with our survey. From our survey, associations with these age related and expected features of the study population did not significantly contribute to the wide scatter of lipid profiles seen and the consequent difficulties in their interpretation. Their identification does not strengthen arguments for and give added value to untargeted lipid screening in the elderly.

1 Ettinger WH, Wahl PW, Kuller LH, Bush TL, Tracy RP, Manolio TA, et al. Lipoprotein lipids in older people. Results from the cardiovascular health study. Circulation 1992;86:858-69.

2 Benefante $\mathrm{R}$, Reed $\mathrm{D}$. Is elevated serum cholesterol a risk factor for coronary heart disease in the elderly? $f A M A$ 1990;263:393-6.

3 Barrett-Connor E. Hypercholesterolaemia predicts early death from coronary heart disease in elderly men but no women: The Rancho Bernado Study. Ann Epidemiol 1992 2:77-83.

4 Zimetbaum P, Frishman WH, Ooi WL, Derman MP, Aronson M, Gidez LI, et al. Plasma lipids and lipoproteins Aronson $\mathrm{M}$, Gidez LI, et al. Plasma lipids and lipoprotein elderly. The Bronx Aging Study. Arterioscler Thromb 1992; elderly. The

5 Forett B, Tortrat D, Wolmark Y. Cholesterol as a risk factor for mortality in elderly women. Lancet 1989;336:868-70.

6 Garber AM, Littenberg B, Sox H, Wagner JL, Gluck M. Costs and health consequences of cholesterol screening for asymptmatic older Americans. Arch Intern Med 1991; 151:1089-95.

7 Hazzard WR. Dyslipoproteinaemia in the elderly. Should it be treated? Clin Geriatr Med 1992;8:89-102.

8 Howard BV. Lipoprotein metabolism in diabetes mellitus. 7 Lipid Res 1987;28:613-28.

9 Ball MJ, Griffiths D, Thorogood M. Asymptomatic hypothyroidism and hypercholesterolaemia. $\mathcal{f} R$ Soc Med $1991 ; 84: 527-9$.

10 Kihara S, Matsuzawa Y, Kubo M, Nozaki S, Funahashi T, Yamashita $\mathrm{S}$, et al. Autoimmune hyperchylomicronaemia. $N$ Engl f Med 1989;320:1255-9.

11 Glueck CJ, Levy RI, Glueck HI, Gralnick HR, Greten H, Fredrickson DS. Acquired type I hyperlipoproteinem with systemic lupus erythematosus, dysglobulinemia an heparin resistance. Am $\mathcal{F}$ Med 1969;47:318-24.

12 Evans P, Pereira Gray D. Value of screening for secondary causes of hyperlipidaemia in general practice. BMF 1994; 309:509-10.

13 Jagger C, Clarke M, Clarke S. Getting older-feeling younger: the changing health profile of the elderly. Int $\mathcal{F}$ Epidemiol 1991;20:234-8.

14 Folstein MF, Folstein SE, McHugh PR. Mini-Mental State: a practical method for grading the cognitive state of patients for the clinician. $\mathcal{F}$ Psychiatr Res 1975;12:189-98.

15 Roth M, Tym E, Mountioy CQ, Huppert FA, Hendrie H, Verma $S$, et al. CAMDEX a standardised instrument for the diagnosis of mental disorder in the elderly with special reference to the early detection of dementia. BrF Psychiatry 1986;149:698-703.

16 Clarke M, Jagger C, Anderson J, Battcock T, Kelly F, Campbell Stern $M$. The prevalence of dementia in a total population: a comparison of two screening instruments. Age Ageing 1991;20:396-403.

17 Mann JI, Lewis B, Shepherd J, Winder AF, Fenster S, Rose $\mathrm{L}$, et al. Blood lipids and other cardiovascular risk factors; their prevalence in Britain. BMF 1988;296:1702-6.

18 Kervinen K, Savolainen MJ, Salokannel J, Hyninnen A, Heikkinen J, Ehnholm C, et al. Apolipoprotein E and B polymorphisms-longevity factors assessed in nonagolymorphisms-longevity factors asserescleris 1994;105:89-95.

19 Berg K, Ro OC. Lp(a) lipoprotein and longevity. Ann Genet 1991;34:264-9.

20 Tunbridge WMG, Evered DC, Hall R, Appleton D, Brewis $\mathrm{M}$, Clark F, et al. Lipid profiles and cardiovascular disease in the Whickham area with particular reference to thyroid failure. Clin Endocrinol 1977;7:495-508.

21 Pocock SJ, Seed PT. Cholesterol in elderly women. Lance 1992;339:1426.

22 Thompson GR. Cholesterol and the plasma lipoproteins. Chapter 17. In: M Hodgkinson, ed. Clinical biochemistry of the elderly. Edinburgh: Churchill Livingstone, 1984: 296-311.

23 Anderson KM, Castelli WP, Levy D. Cholesterol and mortality. 30 years of follow-up from the Framingham Study. tality. 30 years of follow-up
$\mp A M A \quad 1987 ; 257: 2176-80$.

24 Barrett-Connor E, Criqui MH, Witztum JL, Philippi T, Zettner A. Population-based study of glycosylated haemoglobin, lipids and lipoproteins in non diabetic adults Arteriosclerosis 1987;7:66-70.

25 Aviram M, Luboshitsky RR, Brook J. Lipid and liproprotein pattern in thyroid dysfunction and the effect of therapy. Clin Biochem 1982;15:62-6.

26 Bogner U, Arntz H-R, Peters H, Schleusener H. Subclinical hypothyroidism and hyperlipoproteinaemia: indiscriminate L-thyroxine treatment not justified. Acta Endocrinol 1993;128:202-6.

27 Series JJ, Biggart EM, O'Reilly DS St J, Packard CJ, Shepherd J. Thyroid dysfunction and hypercholesterolShepherd J. Thyroid dysfunction and hypercholesterolActa 1988;172:217-21.

28 O'Kane M, Neely RDG, Trimble ER, Nicholls DP. The incidence of asymptomatic hypothyroidism in new referrals to a hospital lipid clinic. Ann Clin Biochem 1991 28:509-11.

29 Glueck CJ, Lang J, Tracy T, Speirs J. The common finding of covert hypothyroidism at initial clinical evaluation for hyperlipoproteinaemia. Clin Chim Acta 1991;201:113-22.

30 Florkowski CM, Cramb R, Hughes EA. The incidence of asymptomatic hypothyroidism in new referrals to a hospital lipid clinic. Ann Clin Biochem 1992;29:237-8.

31 Jackson R, Beaglehole R. Evidence-based management of dyslipidaemia. Lancet 1995;346:1440-1.

32 Haq IU, Jackson PR, Yeo WW, Ramsey LE. Sheffield risk and treatment table for cholesterol lowering for primary prevention of coronary heart disease. Lancet 1995;346: 1476-81.

33 Jacobs D, Blackburn H, Higgins $M$, Reed D, Hiroyasu I McMillan G, et al. Report of the conference on low blood cholesterol: mortality associations. Circulation 1992;86: 1046-60.

34 Johnson WD, Brenowitz JB, Kayser KL. Factors influencing long-term (10-year to 15-year) survival after a successful coronary artery bypass operation. Ann Thorac Surg 1989; 48:19-25.

35 Horvath KA, DiSesa VJ, Peigh PS, Couper GS, Collins JJ, Cohn LH. Favourable results of coronary bypass grafting in patients older than 75 years. 7 Thorac Cardiovasc Surg 1990;99:92-6.

36 Brown BG, Zhao X-Q, Sacco DE, Albers JJ. Lipid lowering and plaque regression: new insights into plaque regression and clinical events in coronary disease. Circulation 1993; 87:1781-91

37 Cosgrove DM, Loop F, Lytle BW, Gill CC, Golding LAR, Gibson C, et al. Determinants of 10-year survival after primary myocardial revascularisation. Ann Surg 1985;202. $480-90$.

38 Scandinavian Simvastatin Survival Group. Randomised trial of cholesterol lowering in 4444 patients with coronary of cholesterol lowering in 4444 patients with coronary Study. Lancet 1994;344:1383-9.

39 Shepherd J, Cobbe S, Ford I, Isles G, Lorimer AR, MacFarlane PW, et al. Prevention of coronary heart disease with Pravastatin in men with hypercholesterolaemia. $N$ Engl f Med 1995;333:1301-7.

40 La Rosa JC, Applegate W, Crouse JR III, Hunninghake DB, Grimm R, Knapp R, et al. Cholesterol lowering in the elderly. Results of the cholesterol reduction in seniors program. Arch Intern Med 1994;154:529-39.

41 Kario K, Matsuo T. Lipid-related hemostatic abnormalities in the elderly: imbalance between coagulation and fibrinolysis. Atherosclerosis 1993;103:131-8.

42 Skartlien AH, Lyberg-Beckmann S, Holme I, Hjermann I, Prydz H. Effect of alteration in triglyceride levels on factor VII: phospholipid complexes in plasma. Arteriosclerosis 1989;9:798-801.

43 Frishman WH, Ooi WL, Derman MP, Eder HA, Gidez II, Ben-Zeev D, et al. Serum lipids and lipoproteins in advanced age.

44 Gylling H, Strandberg T, Tilvis R, Miettinen TA. Regulation of serum cholesterol level in middle-aged and elderly men. Relationship of cholesterol absorption and synthesis to lipoprotein metabolism. Arterioscler Thromb 1994;14:694700 . 